\title{
A sagração da Portela: música, letra e contexto social na produção de reações estéticas em um samba-enredo ${ }^{1}$
}

\author{
The rite of Portela: music, lyrics and social context in the production of aesthetic \\ responses in a samba-enredo
}

\section{Mauricio Ernica}

Faculdade de Educação da Unicamp, Campinas, São Paulo, Brasil.

ernica@unicamp.br

\section{Sergio Molina}

Faculdade Santa Marcelina, São Paulo, São Paulo, Brasil; Instituto Carlos Gomes, Belém, Pará, Brasil. cpcpop.fasmper@santamarcelina.edu.br

Resumo: Este artigo propõe uma abordagem para o estudo de canções populares que articula a análise sócio-histórica - que diz respeito às relações da obra com o espaço social - com as abordagens musical e linguístico-discursiva de sua estrutura interna, identificando e analisando os elementos responsáveis por produzir reações estéticas. Primeiramente, apresentamos referenciais teóricos baseados, sobretudo, nas obras de Antonio Candido, Lev S. Vigotski, Carlos Sandroni, Simha Arom e Godfried Toussaint. Em seguida, analisamos um caso particular: o samba Portela na avenida, de Mauro Duarte e Paulo César Pinheiro, popularizado na gravação de Clara Nunes.

Palavras-chave: canção; música popular; samba; samba-enredo.

Abstract: This article introduces an approach to popular song that combines socio-historic analysis - which discusses the relationship between the work and its social environment - with the musical-linguistic-discursive aspects of its inner structure. It also seeks to identify and

1 Parte desse texto foi apresentada nos IVèmes Rencontres Internacionnales de l'Intéractionnisme Socio-discursif, na Universidade de Genebra, em julho de 2013, com financiamento da Fapesp. Processo: 13/13644-3. 
ERNICA, Mauricio; MOLINA, Sergio (2016). A sagração da Portela: música, letra e contexto social na produção de reações estéticas em um samba-enredo. Per Musi. Ed. por Fausto Borém, Eduardo Rosse e Débora Borburema. Belo Horizonte: UFMG, n.34, p.177-205.

analyse the elements responsible for the production of musical aesthetic responses. Firstly, the work introduces a series of theoretical frames of reference based on the works of Antonio Candido, Lev S. Vigotski, Carlos Sandroni, Simha Arom and Godfried Toussaint. Secondly, we will analyse a particular case: the samba Portela na avenida by Mauro Duarte and Paulo César Pinheiro, popularized in recording by Clara Nunes.

Keywords: song; Brazilian popular music; samba; samba-enredo.

Data de recebimento: 06/03/2016

Data de aprovação final: 06/04/2016

\section{1 - A canção como objeto de estudo}

Objeto semiótico de estrutura complexa, a canção popular é formada pela interconexão de estruturas musicais e verbais. Composta e veiculada no interior de relações e coerções de uma determinada estrutura social, a canção popular muitas vezes volta-se a elas influenciando-as, por exemplo, por meio da reação estética e por meio da circulação e validação de certas representações sociais. Como acontece com as demais manifestações artísticas, as canções possuem, ainda, a faculdade de sobreviver ao contexto histórico em que foram produzidas, assumindo sentido em outras realidades.

A partir da análise do fonograma do samba Portela na avenida, de Mauro Duarte e Paulo César Pinheiro, na gravação de Clara Nunes de 1981, este trabalho tem por objetivo a proposição de elementos teóricos para uma abordagem da canção que articule a abordagem sócio-histórica que trata das relações da canção com o espaço social - com as abordagens musical e linguísticodiscursiva de sua estrutura interna, identificando e analisando os elementos responsáveis por produzir reações estéticas.

Inicialmente, serão expostas referências teóricas baseadas nas obras, sobretudo, de Antonio CANDIDO (1976, 1993, 1995, 2003), de VIGOTSKI (1925a, 1925b, 1934) e de autores vinculados à tradição vigotskiana (CLOT, 2002, 2003; BRONCKART, 1999). Em seguida apresentaremos ferramentas para uma análise musical da canção, que subsidiará a análise da 
ERNICA, Mauricio; MOLINA, Sergio (2016). A sagração da Portela: música, letra e contexto social na produção de reações estéticas em um samba-enredo. Per Musi. Ed. por Fausto Borém, Eduardo Rosse e Débora Borburema. Belo Horizonte: UFMG, n.34, p.177-205.

relação letra-música. Para a análise musical, utilizaremos os trabalhos de SANDRONI (2001), Simha AROM (1991) e TOUSSAINT (2013), que, associados, contribuem para a construção de uma abordagem que contemple os diferentes expedientes rítmicos que a música popular pode congregar.

\section{2 - Uma perspectiva sociológica que considera a estrutura interna da canção}

Nessa abordagem, a análise das canções procura levar em conta dois aspectos centrais. Em primeiro lugar, assume-se que a obra se constitui pela apropriação e transformação de elementos do contexto externo em elementos da sua estrutura interna, tanto no que diz respeito à sua forma quanto ao seu conteúdo (CANDIDO, 1976). Em segundo lugar, a obra pode ter a capacidade de produzir sentido e efeito estético além do contexto de surgimento, não sendo necessariamente "datada" (VOLOCHINOV, 1981). A articulação entre esses dois aspectos nos permite ver o acervo de canções de um dado grupo social como uma espécie de patrimônio histórico-cultural pelo qual se produzem e reproduzem representações sociais e que é portador de possibilidades de formação das pessoas no interior de uma certa tradição (CANDIDO, 1995, 2003; VIGOTSKI, 1925b).

Seguindo o caminho aberto por Antônio CANDIDO (1976), recusa-se aqui a dicotomia entre a análise externa e interna da obra de arte. As abordagens externas, ou contextualistas, consideram as obras, situadas na realidade em que surgem, como objetos que só podem existir porque foram criados por um autor, que tem uma biografia, que vive sob certas condições, submetido a constrangimentos e determinações, que se relaciona com um certo campo artístico e com um determinado público. Contudo, tais abordagens têm alcance restrito por não conseguirem explicar a obra como objeto que existe em si e que instaura uma realidade própria - a realidade artística.

As abordagens internas, por sua vez, tendem a tomar a obra em si mesma, como estrutura significante isolada do contexto em que foi criada e tendem a não considerar suas consequências para a consolidação de sentidos sobre a vida social. Consideram, portanto, a obra 
ERNICA, Mauricio; MOLINA, Sergio (2016). A sagração da Portela: música, letra e contexto social na produção de reações estéticas em um samba-enredo. Per Musi. Ed. por Fausto Borém, Eduardo Rosse e Débora Borburema. Belo Horizonte: UFMG, n.34, p.177-205.

como uma realidade em si e desenvolvem instrumentais adequados à análise de sua estrutura interna. Contudo, também têm um alcance analítico restrito por não poderem explicar como as obras surgem socialmente, como se relacionam com seu tempo, quais sentidos produzem para contribuir com a vida social, quais possibilidades de formação humana têm e como podem chegar a fazer sentido em outros contextos que não aqueles em que surgiram.

Antônio CANDIDO (1993) se propõe a superar essa dicotomia ao analisar a formação da literatura brasileira pelo conceito de sistema literário. Seu objetivo é compreender a formação histórica de uma estrutura com continuidade no tempo e que é constituída por autores, obras e público. De algum modo, ao levar em conta relações de poder entre agentes e as posições resultantes em um sistema de relações, seu conceito de sistema literário se aproxima do conceito de campo cunhado por BOURDIEU. Este último também foi criado para dar conta da superação dessa mesma dicotomia, destacando uma esfera social intermediária, entre as macroestruturas e a biografia dos autores, que seria determinante para conformar as obras de arte, as trajetórias dos artistas e suas relações com o público (BOURDIEU, 2007, 2011; CHAMPAGNE; CHRISTIN, 2012).

A partir desses autores, assumimos neste trabalho que, na composição de uma obra no quadro das relações definidas em um dado campo artístico, são mobilizados conteúdos e formas disponíveis socialmente. Assim, aspectos da vida social exteriores à obra são recriados como elementos de sua estrutura interna. Essa estrutura interna tem uma lógica própria e instaura uma ordem de realidade singular, especificamente artística.

A superação da dicotomia externo/interno pode ser construída postulando-se a relativa autonomia das obras em relação ao seu contexto de produção e circulação imediato. É por sua capacidade de sobreviver ao contexto, fazendo-se duradouras, que as obras contribuiriam para criar um patrimônio cultural de tipo particular, marcado por determinadas formas de descrever, interpretar e valorar a realidade social, o que, por sua vez, contribuiria para difundir formas específicas de perceber e pensar o mundo e formas de socialização das emoções.

VOLOCHINOV (1981), em texto célebre em que analisa a linguagem na arte e na vida, sustenta 
ERNICA, Mauricio; MOLINA, Sergio (2016). A sagração da Portela: música, letra e contexto social na produção de reações estéticas em um samba-enredo. Per Musi. Ed. por Fausto Borém, Eduardo Rosse e Débora Borburema. Belo Horizonte: UFMG, n.34, p.177-205.

que, no curso da vida cotidiana, a compreensão de um discurso depende de uma série de elementos de contexto partilhados pelos interlocutores. Na obra de arte, isso não ocorre igualmente; para ser compreendida, ela precisa interiorizar referências contextuais, recriandoas em seu interior. Por isso, pode se descolar do seu contexto de produção, produzindo sentido e efeito estético para além dele. Por decorrência, podemos pensar que a maior ou menor dependência de elementos exteriores, contextuais, é que faz uma obra de arte ser mais ou menos enraizada em um momento histórico ou em uma prática social.

A formação histórica da canção popular exigiu sua autonomização em relação às situações imediatas de produção e apropriação. As músicas vinculadas a celebrações (profanas ou religiosas) não tinham os contornos dos gêneros emergentes do cancioneiro urbano e eram ligadas a conteúdos, pessoas e intrigas do seu contexto imediato e do grupo que as praticava. Ali, mediavam relações sociais. Ao serem transformadas para o registro em fonogramas e ao circularem pelos modernos meios de comunicação, inicialmente o rádio e o disco, posteriormente a TV, essas músicas, de mediações de relações sociais, tornaram-se obras relativamente autônomas do contexto imediato de veiculação (MARTINS, 1975).

Dado que as canções podem se desprender do contexto imediato de produção e circulação, elas podem integrar o patrimônio artístico de um grupo. Assim, uma vez que contribuem para a formação do pensamento e da sensibilidade de novas gerações, estabelecem continuidades entre elas e as gerações passadas. Também por essa razão, o cancioneiro constitui um imenso acervo documental sobre a visão de mundo e o patrimônio estético de grupos que não necessariamente deixaram documentos escritos sobre isso.

Partindo da premissa de que, no Brasil, as tradições culturais letradas são pouco difundidas, José Miguel WISNIK, em depoimento ao filme A palavra en-cantada (SOLBERG, 2008), argumenta que a música popular ocuparia aqui um papel que a poesia e as artes letradas exerceram em outras culturas.

Acho que a literatura, quer dizer, a cultura letrada nunca se implantou completamente no Brasil (...). Passou-se muito diretamente dos meios orais pro rádio e pra televisão, pros meios audiovisuais. Eu sinto (...) o quanto a música popular permite você estabelecer um contato entre a literatura e o repertório (...) [das novas] gerações. Criou-se uma situação que não existe propriamente em país nenhum desse jeito, que é uma canção popular fortíssima, que ganhou uma 
capacidade (...) de cantar para auditórios imensos e levar pra esses auditórios poesia de densa qualidade, de sutileza, de riqueza (...) (WISNIK citado por SOLBERG, 2008, 20'15"-21'40").

\section{3 - Uma abordagem que leva em conta a reação estética gerada pela canção}

Um outro elemento a ser considerado na análise da canção é a experiência estética que ocorre quando alguém se apropria de uma obra de arte e as consequências dessa experiência para o sujeito. Aportes importantes para desenvolver esse ponto estão presentes também na obra Antonio CANDIDO (1995, 2003). Essas ideias, embora elaboradas para a análise da obra literária, podem, por sua generalidade, ser empregadas para a análise da canção.

0 autor especifica três funções da arte, que se inter-relacionam. A primeira é a de satisfazer a necessidade humana de fabulação, de construção de realidades imaginadas que permitem às pessoas viver intensamente experiências “outras” em relação ao ordinário.

A segunda é a função de formação humana, assim definida:

As criações ficcionais e poéticas podem atuar de modo subconsciente e inconsciente, operando uma espécie de inculcamento que não percebemos. Quero dizer com isso que camadas profundas de nossa personalidade podem sofrer um bombardeio poderoso das obras que lemos e que atuam de maneira que não podemos avaliar. Talvez os contos populares, as historietas ilustradas, os romances policiais ou de capa-e-espada, as fitas de cinema, atuem tanto quanto a escola e a família na formação de uma criança e de um adolescente (CANDIDO, 2003, p.82).

Ou ainda:

Os valores que a sociedade preconizará, ou que considera prejudiciais, estão presentes nas diversas manifestações da ficção, da poesia e da ação dramática. A literatura confirma e nega, propõe e denuncia, apoia e combate, fornecendo possibilidades de vivermos dialeticamente os problemas (CANDIDO, 1995, p.243).

Ao abordar os conflitos valorativos existentes nas obras de arte, o autor afirma o seguinte:

[Há] conflito entre a ideia convencional de uma literatura que eleva e edifica (segundo os padrões oficiais) e a sua poderosa força indiscriminada de iniciação na vida, com uma variada complexidade nem sempre desejada pelos educadores. Ela não corrompe nem edifica, portanto; mas, trazendo livremente em si o que chamamos o bem e o que chamamos o mal, humaniza em sentido profundo, porque faz viver (CANDIDO, 1995, p.85). 
ERNICA, Mauricio; MOLINA, Sergio (2016). A sagração da Portela: música, letra e contexto social na produção de reações estéticas em um samba-enredo. Per Musi. Ed. por Fausto Borém, Eduardo Rosse e Débora Borburema. Belo Horizonte: UFMG, n.34, p.177-205.

Além das funções de satisfazer a necessidade universal de fantasia e de contribuir para a formação da personalidade, CANDIDO destaca uma terceira função: produzir conhecimento sobre o mundo e sobre o ser, o que se relaciona diretamente com as representações do mundo e do humano presentes nas obras.

O autor continua: a estrutura da obra é fundamental para que ela possa exercer suas três funções.

\begin{abstract}
Quando elaboram uma estrutura, o poeta ou o narrador nos propõem um modelo de coerência, gerado pela força da palavra organizada. Se fosse possível abstrair o sentido e pensar nas palavras como tijolos de uma construção, eu diria que esses tijolos representam um modo de organizar a matéria, e que enquanto organização eles exercem papel ordenador de nossa mente. Quer percebamos claramente ou não, o caráter de coisa organizada da obra literária torna-se um fator que nos deixa mais capazes de ordenar a nossa própria mente e sentimentos; e em consequência, mais capazes de organizar a visão que temos do mundo (CANDIDO, 1995, p.245).
\end{abstract}

Em suma, a estrutura da obra é importante para que possamos organizar primeiramente a nós mesmos e, depois, o mundo; é importante para que possamos produzir sentidos sobre nós mesmos e sobre o mundo. Como veremos, no caso da canção, esses "tijolos" que compõem a estrutura da obra podem ser elementos de natureza musical ou verbal e também elementos resultantes das diversas formas de enlace pelas quais som e palavra podem se amalgamar.

Essas teses de CANDIDO são, globalmente, compatíveis com as de VIGOTSKI², para quem nos formamos como pessoas dessa ou daquela sociedade ao internalizarmos e nos apropriarmos de relações sociais - de instrumentos de regulação social que existiam antes no meio social - que, ao serem transferidas para nosso interior, se tornam componentes estruturantes de nosso psiquismo.

Esses recursos sociais dos quais nos apropriamos permitem que experiências vividas sejam transformadas e generalizadas em categorias sociais. A consciência do outro torna-se elemento da consciência de si e, por esse processo de generalização de experiências por categorias sociais,

2 Remetemos o leitor para ERNICA (2006) para uma discussão mais detalhada dessas ideias. 
ERNICA, Mauricio; MOLINA, Sergio (2016). A sagração da Portela: música, letra e contexto social na produção de reações estéticas em um samba-enredo. Per Musi. Ed. por Fausto Borém, Eduardo Rosse e Débora Borburema. Belo Horizonte: UFMG, n.34, p.177-205.

a pessoa pode tomar a si própria como objeto de sua ação, processo pelo qual ela se torna sujeito de ação. Por essas categorias, as pessoas podem, com sucesso relativo, tomar o mundo como realidade já vista e podem fazer uso de seus próprios recursos psíquicos e físicos tendo em vista a satisfação de suas necessidades, a auto orientação de suas ações e a realização de suas potencialidades.

Porém, esse processo de construção social do psiquismo e do comportamento não abarca todas as experiências vividas pelo sujeito. No curso da vida que se realiza a cada dia nascem, em estado de potência, muitas outras vidas possíveis e as estruturas socialmente formadas de nosso psiquismo deixam de fora um conjunto de experiências que não puderam ser formalizadas, não puderam ganhar forma social. Portanto, a vida que realizamos a cada dia é mais restrita do que ela pode ser. Em suas palavras:

\begin{abstract}
Nunca se pode admitir que essa equilibração se realiza até o fim de maneira harmoniosa e plena, [pois] sempre haverá certas oscilações da nossa balança, sempre haverá certa vantagem da parte do meio ou do organismo. (...) Sempre existem estímulos de energia que não podem encontrar vazão livre para equilibrar nossa balança com o mundo (...). Basta olhar para uma criança e se perceberá que nela há muito mais possibilidades de vida do que aquelas que se realizam (...). 0 nosso sistema nervoso lembra uma estação para a qual confluem cinco ferrovias mas da qual só por uma há partida; de cada cinco trens que ali chegam, apenas um consegue irromper para fora, e assim mesmo depois de uma luta cruel, pois os outros quatro permanecem na estação. Assim, o sistema nervoso lembra um campo de batalha permanente, e nosso comportamento realizado representa uma ínfima parte do que existe em forma de possibilidade, que foi acionado mas não encontra vazão (VIGOTSKI, 1925b, p.311-312).
\end{abstract}

A vida realizada responde apenas a uma pequena parcela da vida que pode ser vivida. A vida possível e não realizada é muito mais vasta que a vivida porque o real de nossa vida é composto também pelo que não podemos fazer, pelo que não conseguimos realizar, pelo que nos é sonegado, pelo que nos é impedido, por nossas hesitações, pelo não que dizemos em cada escolha, pelo que só podemos fazer com o auxílio de um outro, pelo que até chegamos a fazer mas que não conseguimos fazer de novo, voluntária e autonomamente (CLOT, 2002; 2003). Enfim, todo esse universo fragmentado, disperso e não formalizado constitui um universo residual de experiências possíveis, muito embora não realizadas.

O desenvolvimento pode ser pensado, portanto, como o processo pelo qual as pessoas passam 
ERNICA, Mauricio; MOLINA, Sergio (2016). A sagração da Portela: música, letra e contexto social na produção de reações estéticas em um samba-enredo. Per Musi. Ed. por Fausto Borém, Eduardo Rosse e Débora Borburema. Belo Horizonte: UFMG, n.34, p.177-205.

a incorporar, no seu presente, como parte do novo vivido, um acervo de experiências passadas que guardavam novas possibilidades de viver, desde que generalizadas em categorias sociais 3 . Sobre o papel da obra de arte no desenvolvimento, VIGOTSKI afirma:

Essa parte não realizada da vida (...) deve ser eliminada de alguma maneira. 0 organismo foi colocado em certo estado de equilíbrio com o meio, é necessário regular a balança como é necessário abrir a válvula na caldeira em que a pressão do vapor supera a resistência do seu corpo. Eis que a arte é, parece ser, o veículo adequado para atingir esse equilíbrio explosivo com o meio nos pontos críticos do nosso comportamento. Há muito tempo se externava a ideia segundo a qual a arte parece completar a vida e ampliar as suas possibilidades (VIGOTSKI, 1925b, p.313).

Compreende-se, desse modo, por que a arte permite que as emoções inconscientes ganhem um meio de expressão por meio de formas sociais. Para o autor, na medida em que são exprimidas e transformadas pela emoção artística, as emoções inconscientes podem ganhar uma forma social e integrar as funções psicológicas superiores do sujeito. É neste sentido que ele afirma que

(...) a arte é uma técnica social do sentimento, um instrumento da sociedade através do qual incorpora ao ciclo da vida social os aspectos mais íntimos e pessoais do nosso ser. Seria mais correto dizer que o sentimento não se torna social mas, ao contrário, torna-se pessoal, quando cada um de nós vivencia uma obra de arte, converte-se em pessoal sem com isso deixar de continuar social (VIGOTSKI, 1925b, p.315).

Se é assim, podemos dizer que os sentimentos que são experimentados e socializados pela arte são projetados em direção a novas ações. "A arte é antes uma organização do nosso comportamento visando ao futuro, uma orientação para o futuro, uma exigência que talvez nunca venha a concretizar-se, mas que nos leva a aspirar acima da nossa vida o que está por trás dela" (VIGOTSKI, 1925b, p.315).

A arte, ao realizar essa "descarga de energia nervosa", faz com que essas emoções passem a ser mediadas pelo pensamento verbal; logo, emoções que o sujeito pode tomar para si mesmo, pode colocar sob seu controle e como meio para novas ações. Enfim, "as emoções da arte são emoções inteligentes. Em vez de se manifestarem de punhos cerrados e tremendo, resolvem-se em imagens da fantasia" (VIGOTSKI, 1925b, p.167).

3 Para uma discussão mais detalhada, cf. ERNICA (2008). 
ERNICA, Mauricio; MOLINA, Sergio (2016). A sagração da Portela: música, letra e contexto social na produção de reações estéticas em um samba-enredo. Per Musi. Ed. por Fausto Borém, Eduardo Rosse e Débora Borburema. Belo Horizonte: UFMG, n.34, p.177-205.

As emoções suscitadas e socializadas pela arte se resolvem na apropriação da arte e não geram uma ação imediata. Como nos sonhos, nos devaneios e nas figurações da fantasia, as emoções mobilizadas pela arte não resultam em ações sobre o mundo exterior. Nas obras de arte, "a descarga de energia nervosa, que constitui a essência de todo sentimento" (VIGOTSKI, 1925b, p.167) se realiza de modo oposto ao habitual, retendo sua manifestação externa e conservando no sujeito uma força excepcional. 0 autor afirma, por exemplo, que a música militar não produz ação, mas induz a um impulso vago de agir que pode ser mobilizado por certas estruturas sociais.

\section{4 - A produção da reação estética: forma, conteúdo e catarse}

A retenção da manifestação das emoções em ações exteriorizadas acontece porque a arte faz conviver estímulos contraditórios, o que paralisa a ação sobre o mundo que poderia ser decorrente. Fazendo uma referência a Hamlet, VIGOTSKI afirma que "é como se a tragédia nos levasse a praticar movimentos simultâneos para a direita e a esquerda, levantar e abaixar ao mesmo tempo um peso, é como se excitasse ao mesmo tempo um músculo e seus antagonistas" (VIGOTSKI, 1925b, p.320).

Portanto, como a arte pode gerar a coexistência de planos emocionais que se contradizem, ela pode também fazer com que um plano intensifique e negue o outro. Assim, a arte criaria um acúmulo de energia que seria represada progressivamente à espera de alguma forma de expressão: a produção de figuras da imaginação.

Toda obra de arte encerra forçosamente uma contradição emocional, suscita séries de sentimentos opostos entre si e provoca seu curto-circuito e destruição. A isso podemos chamar o verdadeiro efeito da obra de arte, e com isso nos aproximamos em cheio do conceito de catarse (VIGOTSKI, 1925b, p.269).

Dessa perspectiva, a arte destrói as tensões emocionais que mobilizou e represou por meio da liberação da energia psíquica que define a solução catártica ${ }^{4}$. Mas como se produz a catarse?

4 Recuperaremos essa questão na análise final de Portela na avenida, quando proporemos soluções para o embate entre as noções de "estado" e "processo" no que concerne ao encaminhamento do tempo. 
ERNICA, Mauricio; MOLINA, Sergio (2016). A sagração da Portela: música, letra e contexto social na produção de reações estéticas em um samba-enredo. Per Musi. Ed. por Fausto Borém, Eduardo Rosse e Débora Borburema. Belo Horizonte: UFMG, n.34, p.177-205.

Para VIGOTSKI, pelo conflito entre conteúdo e forma. Em Psicologia da arte, o conteúdo é definido como representações que foram mobilizadas pelo artista para a definição do mundo que é construído na obra. A forma é definida por VIGOSTSKI como a disposição desse conteúdo temático segundo as leis da construção artística. 0 conteúdo mobiliza emoções e a forma ordena e transforma essas emoções ao colocar os elementos do conteúdo em relação.

O conteúdo pode ser descrito em unidades e pode ser disposto numa temporalidade linear de acontecimentos. Os protagonistas podem ser isolados; os eventos a eles associados, organizados cronologicamente. Desse modo podemos ver elementos potencialmente criadores de tensão, mas não as tensões entre os planos de emoções e muito menos a solução catártica. No caso da canção, esses "protagonistas" podem ser personagens das narrativas da letra, mas também, em termos estritamente musicais, podem ser motivos melódicos, células rítmicas, etc.

A forma também pode ter elementos potencialmente criadores de tensão, mas em si e por si mesma não realiza as tensões da obra nem cria as soluções catárticas. É, portanto, na relação conflituosa entre as emoções suscitadas pelo conteúdo e as suscitadas pela forma que a obra de arte pode e deve ser compreendida.

A forma é considerada o princípio ativo porque faz viver, intensifica, apaga e destrói as impressões que os acontecimentos deixam no espectador. Sua organização temporal é a do fluxo e a da duração dos eventos tal como dispostos no mundo artístico. A forma, desse modo, chama à realização as emoções suscitadas pelo conteúdo, mas as retarda. Esse movimento ativo da forma suscita então emoções que contradizem aquelas que são despertadas pelo conteúdo. "A lei da reação estética é uma só: encerra em si a emoção que se desenvolve em dois sentidos opostos e encontra sua destruição no ponto culminante, com uma espécie de curto-circuito" (VIGOTSKI, 1925b, p.270).

É por isso então que VIGOTSKI fala da lei da destruição do conteúdo pela forma. Ao final, os movimentos gerados pela forma fazem com que, a partir das emoções vividas até o instante da catarse, sejam criadas outras emoções, distintas das anteriores. O que foi vivido como 
ERNICA, Mauricio; MOLINA, Sergio (2016). A sagração da Portela: música, letra e contexto social na produção de reações estéticas em um samba-enredo. Per Musi. Ed. por Fausto Borém, Eduardo Rosse e Débora Borburema. Belo Horizonte: UFMG, n.34, p.177-205.

brutalidade pode ser transformado num leve alento, como no conto ${ }^{5}$ analisado pelo autor, e o que foi relutância e adiamento da resolução - na trama de Hamlet - se transforma no acaso que gera a série de mortes não planejadas do desfecho da tragédia6.

\section{5 - Fricções e complementariedades rítmicas: Portela na avenida}

As referências teóricas acima podem ser mobilizadas para a análise da canção popular. Como vimos, por se tratar de um objeto semiótico híbrido, na canção há tensões ${ }^{7}$ geradoras de reação estética, tanto no interior de suas estruturas verbais e musicais quanto nas estruturas produzidas pelos diferentes enlaces possíveis entre as duas linguagens.

O samba é um gênero que se definiu no Brasil forjado, em linhas gerais, pela fricção de propriedades rítmicas de ascendência africana e de propriedades melódico-harmônicas de origem europeia. Diversos autores (TINHORÃO, 1998; SEVERIANO e MELLO, 1997; MOURA, 1983; VIANNA, 1999) apontam as primeiras décadas do século XX como decisivas para a formação do samba urbano, que teria sido redefinido a partir de um campo artístico criado no Rio de Janeiro. A partir dos anos 1930, quando o samba urbano enfim alcança sua primeira maturidade, subgêneros vão sendo elaborados em função de práticas sociais específicas e de determinados elementos estruturais.

Desde que o campo musical se consolidou no Rio de Janeiro, pela mediação da indústria cultural e de práticas como o carnaval, obras foram compostas para homenagear e celebrar as glórias de regiões e grupos da cidade, por vezes dando origem a disputas pela primazia do samba e dos sambistas de um lugar sobre os de outro 8 .

5 Cf. VIGOTSKI (1925b), especialmente o capítulo sete, dedicado à análise do conto “Leve alento", de Ivan Búnin. 6 Cf. VIGOTSKI (1925b), especialmente o capítulo oito, dedicado à análise de Hamlet. Cf. também VIGOTSKI (1917). 70 termo "tensão" é utilizado neste artigo para nomear os conflitos, no interior de uma obra, produtores de reação estética, e não em sentido específico, referindo-se a notas que estabelecem tensão harmônica, ou a algum determinado acorde de tensão em um determinado contexto harmônico.

8 Algumas batalhas musicais travadas desde os anos 1920 tornaram-se célebres, como a protagonizada por Sinhô e o círculo ao qual pertencia Pixinguinha ou como a protagonizada, na década seguinte, por Noel Rosa e Wilson Batista. 
ERNICA, Mauricio; MOLINA, Sergio (2016). A sagração da Portela: música, letra e contexto social na produção de reações estéticas em um samba-enredo. Per Musi. Ed. por Fausto Borém, Eduardo Rosse e Débora Borburema. Belo Horizonte: UFMG, n.34, p.177-205.

Em fins dos anos 1930, já com o samba redefinido como símbolo nacional, surge o subgênero que ficaria conhecido como samba-exaltação, com letras orientadas para cantar e engrandecer a nação ${ }^{9}$. Nos anos 1940, com o samba consolidado como gênero por excelência do carnaval carioca e com os desfiles já bastante regulados e orientados para competição, um outro subgênero, o samba-enredo, é oficializado como exigência para as escolas se apresentarem na passarela.

Os anos 1950 foram a década do samba-canção (em meio ao grande sucesso do baião de Luiz Gonzaga e do bolero), das primeiras experiências de samba-jazz (Johnny Alf) e da lenta gestação de um outro subgênero que mais tarde se autonomizaria, a bossa-nova de Tom Jobim e João Gilberto. Assim, nos anos 1960, o campo da música popular brasileira seria composto por diversos gêneros, ainda que muitos fossem originalmente ligados ao samba.

Nos anos 1970, ao mesmo que tempo em que se verifica uma maior diversificação de gêneros musicais, por exemplo, com a influência do rock e da soul music, há, à esquerda e à direita do espectro político, fortes movimentos nacionalistas que reforçariam o samba e o carnaval como símbolos nacionais. Acontece, nesse período, a retomada e a celebração de sambistas esquecidos - como Cartola - e a reivindicação da filiação ao samba forjado nos anos de 1920 e 1930 por artistas que surgiram vinculados à Bossa Nova - Chico Buarque é, neste aspecto, um caso emblemático. Também nessa década, são compostos sambas que tematizam as transformações no campo musical e no próprio gênero, tais como Argumento, de Paulinho da Viola, sucesso em 1975 (SEVERIANO e MELLO, 1999, p.216), e Não deixe o samba morrer, sucesso em 1976 na interpretação de Alcione composto por dois artistas pouco conhecidos, Edson Gomes da Conceição e Aloísio Silva (SEVERIANO e MELLO, 1999, p.222).

O samba Portela na avenida, de Mauro Duarte e Paulo César Pinheiro, lançado por Clara Nunes no final de 1981 e popularizado no carnaval de 1982 (SEVERIANO e MELO, 1999, p.294-295), foi composto e interpretado por artistas vinculados a essa revalorização do samba nos anos

9 Aquarela do Brasil (1939), de Ary Barroso, é um samba-exaltação exemplar. 
ERNICA, Mauricio; MOLINA, Sergio (2016). A sagração da Portela: música, letra e contexto social na produção de reações estéticas em um samba-enredo. Per Musi. Ed. por Fausto Borém, Eduardo Rosse e Débora Borburema. Belo Horizonte: UFMG, n.34, p.177-205.

1970 e pode ser inscrito na tradição dos sambas que celebram bairros de sambistas e suas escolas de samba - já então erigidos à condição de símbolos nacionais.

Analisaremos um fonograma específico dessa canção, o original de Clara Nunes. Inicialmente, abordaremos elementos musicais que, posteriormente, serão relacionados à análise de sua letra. Nessa canção, de modo contundente, verifica-se o embate gerador de tensões entre propriedades rítmicas e propriedades melódico-harmônicas característico do samba. Formado musicalmente por estruturas geradoras de estímulos contrários, o samba produz emoções de difícil classificação que, não raro, podem ser nomeadas por binômios antitéticos como "melancolia eufórica", "alegria nostálgica", "triste esperança".

A condução rítmica do samba, assim como acontece de maneira geral na música popular urbana, se apresenta normalmente organizada em ciclos de poucos compassos que estabelecem um estado de repetição. É como se essa condução rítmica do samba preservasse, ainda, resquícios da música ritual africana de que descende. A repetição dos ciclos rítmicos, assim, cria um estado de permanência que parece suspender a passagem do tempo, pois não há a inserção de novos elementos significativos, mas sim uma situação geradora de um contínuo presente. Nela, a solução catártica se dá pelo acúmulo de energia que é mobilizada progressivamente na repetição dos ciclos rítmicos, até o ponto em que a retenção dessa energia emocional não pode mais ser contida.

A melodia e a harmonia, por sua vez, são regidas pelo sistema tonal de origem europeia, e sugerem uma trajetória mais linear, com a apresentação e o estabelecimento da tônica como centro gravitacional ao qual se segue um afastamento, pela exploração de outros graus da escala, até se alcançar a tensão na dominante, que, "resolvida", recupera o centro inicial concluindo um determinado período. A melodia, especificamente, tende a funcionar como guia de uma narrativa, instaurando um movimento horizontal muitas vezes atrelado à narrativa verbal, incorporando novas informações e trilhando novos contornos à medida que percorre a linha do tempo e conta uma história.

Ou seja, além de a condução da base rítmica e a melodia-harmonia serem organizadas em ciclos 
ERNICA, Mauricio; MOLINA, Sergio (2016). A sagração da Portela: música, letra e contexto social na produção de reações estéticas em um samba-enredo. Per Musi. Ed. por Fausto Borém, Eduardo Rosse e Débora Borburema. Belo Horizonte: UFMG, n.34, p.177-205.

de extensão distinta, há por trás desse desencaixe uma diferença de natureza que pode ser entendida como situações de "estado" (uma configuração rítmica circular onde o próprio ciclo funciona como uma espécie de centro, um equivalente do tom para a propriedade altura) e de "processo" (com centro-afastamento-centro).

Escrevendo sobre a circularidade temporal em músicas modais, como é o caso da música da África subsaariana, José Miguel Wisnik explica: “(...) isso se faz através do envolvimento coletivo e integrado do canto, do instrumental e da dança, através da superposição de figuras rítmicas assimétricas no interior de um pulso fortemente definido (...)” (WISNIK, 1989, p.71).

O samba-enredo é um subgênero do samba que tem como característica um discurso mais extenso que o padrão. Nele, o contraste entre os ciclos curtos da percussão e a emissão alongada das vogais na melodia da voz se faz mais evidente. Em Portela na avenida, na gravação de Clara Nunes de 1981, podemos observar logo nos primeiros compassos.

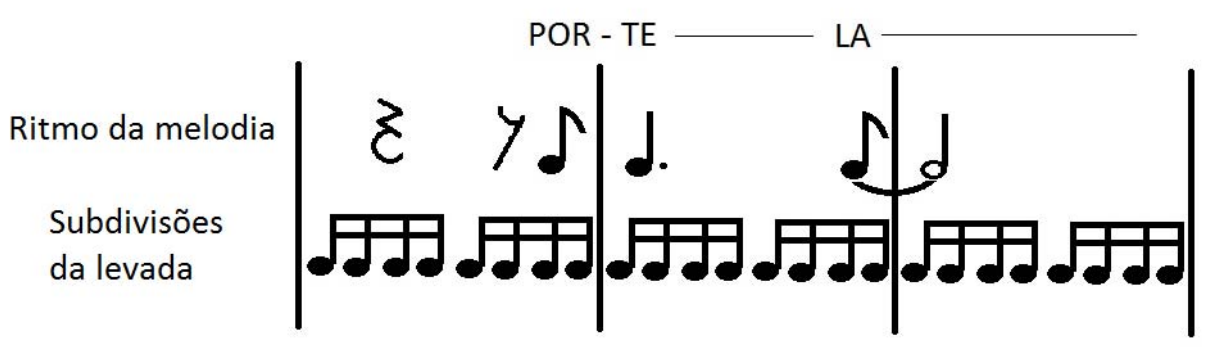

Figura 1: Portela na avenida - ritmos - c.3-5

Essa ilustração representa o que ouvimos no fonograma apenas de forma esquemática, não se tratando precisamente de uma transcrição. Imaginando um contexto que poderia ser notado em 2/4, verifica-se que as articulações mais evidentes da percussão se dão no âmbito das semicolcheias, enquanto que o ritmo da melodia agrupa, já nessa primeira palavra (Portela), duas, seis e dez semicolcheias por sílaba, respectivamente (Por - te - la). 0 ritmo escolhido para representar a melodia é aqui o que poderíamos chamar de "modelo presumido para variações". Funciona como uma divisão tácita subjacente às modificações que o cantor provavelmente fará, a cada vez de uma maneira, mas sempre como variação desse modelo, quase sempre, oculto. Os ataques nas semicolcheias pulsadas podem ser, portanto, antecipados ou deslocados no 
ERNICA, Mauricio; MOLINA, Sergio (2016). A sagração da Portela: música, letra e contexto social na produção de reações estéticas em um samba-enredo. Per Musi. Ed. por Fausto Borém, Eduardo Rosse e Débora Borburema. Belo Horizonte: UFMG, n.34, p.177-205.

instante imediato da performance.

Se com dois compassos ${ }^{10}$ a essência do ciclo da condução rítmica se completa, o caminho da melodia, por sua vez, tomará inicialmente 14 compassos em sua primeira exposição (o segmento "a1" na figura 2 a seguir) ${ }^{11}$. Esses 14 primeiros compassos são repetidos (mesma harmonia) com a melodia estendendo-se até a quinta do acorde, a nota Lá em Ré menor (a2) ${ }^{12}$. Na sequência, ainda na Seção A, há de um novo período de 20 compassos (b) ${ }^{13}$ que explora a região do quarto grau (Sol menor). Os dois primeiros segmentos de 14 compassos são retomados com variações melódicas e de letra (a1' e a2') ${ }^{14}$. Na Seção B o percurso da melodia abarca 28 compassos $^{15}$.

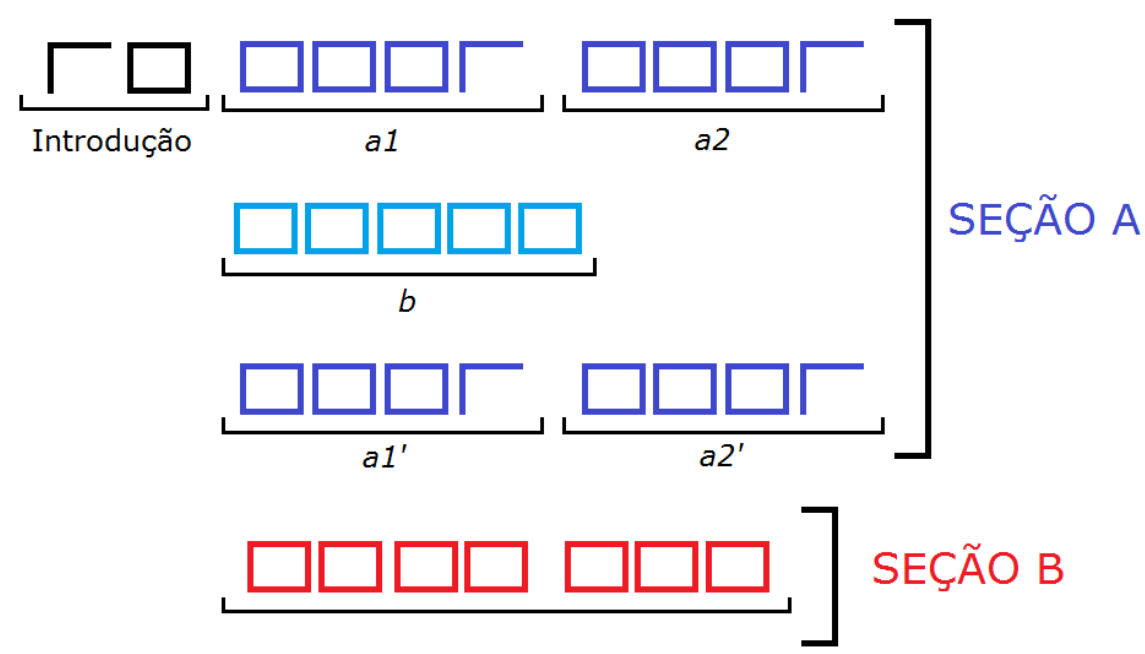

Figura 2: Seções de Portela na avenida ${ }^{16}$

10 No fonograma de Clara Nunes é possível notar, já na introdução entre os compassos 3 e 4, um ciclo que será a referência padrão para a condução do cavaquinho na canção.

11 Versos 1-4. Ver letra completa na seção 6.

12 Versos 5-8.

13 Versos 9-13.

14 Versos 14-17 e 18-21, respectivamente.

15 Versos 22-28.

16 Na Figura 2, cada traço equivale a um compasso (as frases musicais se organizam muitas vezes em quatro compassos, o que equivale, na figura, a um quadrado). Este modelo de representação gráfica da forma - em que cada traço equivale a um compasso - é amplamente utilizado pelo Prof. Ricardo Breim há cerca de 30 anos. 
ERNICA, Mauricio; MOLINA, Sergio (2016). A sagração da Portela: música, letra e contexto social na produção de reações estéticas em um samba-enredo. Per Musi. Ed. por Fausto Borém, Eduardo Rosse e Débora Borburema. Belo Horizonte: UFMG, n.34, p.177-205.

Explorando um pouco mais a complexidade rítmica irradiada pela tensão entre a condução percussiva da base e a melodia, podemos verificar que, por suas próprias características estruturais, a ideia de divisão em compassos no modelo da escrita musical, criada na esfera da música clássica europeia, não dá conta de explicitar os princípios fundamentais que organizam os ataques irregulares da música popular. Os compassos partem da ideia de um ciclo de tempos iguais, que são subdivididos em durações menores, sempre de duas ou três partes iguais. 0 primeiro tempo de cada compasso é acentuado. Já a música da África subsaariana, por outro lado, organiza-se em ciclos assimétricos, em que "tempos" de diferentes durações podem se suceder.

O etnomusicólogo brasileiro Carlos Sandroni, seguindo Simha Arom, explica:

Nossa teoria musical clássica prevê dois tipos de compasso, os simples e os compostos. Nos compassos simples [2/4, 3/4 e 4/4], as unidades de tempo são binárias ${ }^{17}$ semínimas. (...) Por outro lado nos compassos compostos, como o 6/8 e 9/8, as unidades de tempo são ternárias ${ }^{18}$ e são representadas por semínimas pontuadas (divididas portanto em três colcheias). Mas o fato é que não há compassos que misturem de modo sistemático agrupamentos de duas ou três pulsações, como semínimas e semínimas pontuadas. É precisamente esta mistura que vai desempenhar papel muito importante na África subsaariana (SANDRONI, 2001, p.24).

Ou seja, o princípio de organização das durações na música da África subsaariana e também, de certo modo, na música popular das Américas não toma como principal referência a ideia de compasso, mas sim a sequência pulsada (que costumamos chamar de "subdivisões"19), que por serem irregularmente atacadas, estabelecem "tempos" de diferentes durações (ora de duas, ora de três semicolcheias). Em outras palavras, a música africana organiza-se ritmicamente muito mais sobre uma espécie de ostinato que resulta desses ataques irregulares sobre a pulsação subjacente (as "semicolcheias") do que sobre a regularidade simétrica de cada período (as “semínimas"). A chave para a compreensão está em ouvir essa célula resultante, esse ostinato referencial, que foi denominado por Simha AROM de time-lines. Utilizaremos aqui a denominação que se popularizou a partir dos estudiosos cubanos e que também é encontrada

17 Cada tempo pode ser subdividido em duas partes iguais (nota nossa).

18 Cada tempo pode ser subdividido em três partes iguais (nota nossa).

190 equivalente às semicolcheias na Figura 1. 
ERNICA, Mauricio; MOLINA, Sergio (2016). A sagração da Portela: música, letra e contexto social na produção de reações estéticas em um samba-enredo. Per Musi. Ed. por Fausto Borém, Eduardo Rosse e Débora Borburema. Belo Horizonte: UFMG, n.34, p.177-205.

no Brasil: claves $^{20}$.

Em Feitiço decente (SANDRONI, 2001), o autor mostra como o samba, após a década de 1930, passou a se estruturar a partir da seguinte clave rítmica, por ele batizada de o "paradigma do Estácio".

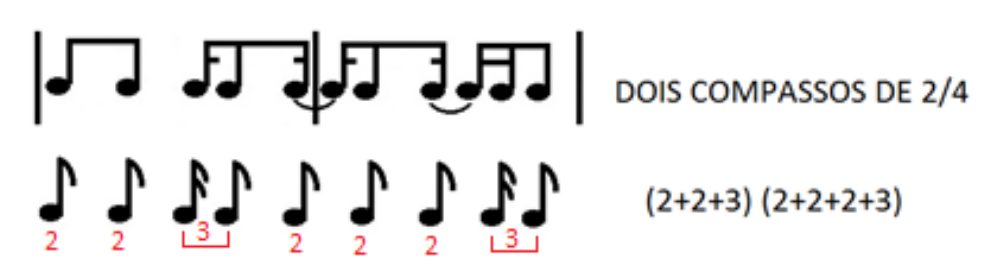

Figura 3: Clave de samba - "paradigma do Estácio"

Na figura acima, a primeira disposição é uma tentativa de adequar ataques e durações irregulares da música popular à escrita "divisiva” e regular criada para a música clássica em geral. O agrupamento da clave em quatro tempos (dois por compasso) não representa visualmente o princípio rítmico que organiza a célula. Já na segunda disposição, que SANDRONI também apresenta em Feitiço decente, podemos visualizar um único ciclo maior em que se percebem "tempos" formados por duas semicolcheias e "tempos" formados por três semicolcheias (sete "tempos" ao todo).

Em The geometry of musical rhythm, Godfried TOUSSAINT argumenta a favor de uma notação rítmica em que o ciclo seja disposto circularmente (clock notation). Essa proposta parece de fato representar melhor a ideia de circularidade (estado) - e não de narrativa (processo) - que estrutura as bases rítmicas na música popular. Além disso, ainda nos fundamentando na ideia de "estado", a disposição em círculo nos permite visualizar diferentes possibilidades de "início", bastando considerar qualquer um dos 16 pulsos como um potencial primeiro ataque, gerando, por decorrência dessas rotações, variações de uma mesma figura rítmica, que, muitas vezes, são utilizadas pelos músicos na prática.

A clave do "paradigma" do samba do Estácio, identificado por SANDRONI, poderia ser notada 20 Claves rítmicas. 
da seguinte maneira.

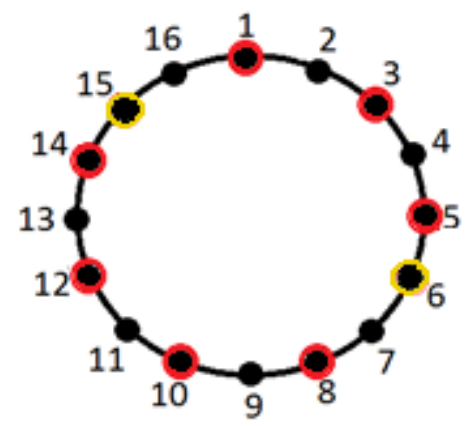

Figura 4: "Paradigma do Estácio" - notação circular²1

Essa disposição, que se baseia no modelo circular proposto por TOUSSAINT, nos permite facilmente visualizar também algumas variações da clave, como uma que é bastante comum e que aconteceria se tomássemos o ponto 9 como início do ciclo.

Mas a questão principal é que não é suficiente afirmar que a rítmica na música popular, devido às suas origens africanas, poderia ser notada de outra forma e que, consequentemente, a escrita de origem europeia não seria o melhor caminho para identificarmos e percebermos os princípios que organizam a condução rítmica, com seus acentos, tempos irregulares, etc.

A questão é que a rítmica na música popular é polirrítmica desde sua gênese na medida em que abriga ao mesmo tempo princípios aparentemente conflitantes - recuperando aqui as proposições de VIGOTSKI: uma base "africana" e uma melodia e harmonia que ainda são regidas pela quadratura "europeia". Daí a necessidade da melodia (e não da harmonia) de vez por outra se filiar também aos acentos assimétricos da condução (como pode ser observado na Figura 1 com a suposta antecipação de um ataque que estaria na cabeça do compasso cinco), servindo então como elemento unificador entre dois princípios contraditórios, um que justapõe ataques assimétricos, cria uma clave e sugere um estado circular, e outro que se filia a compassos

21 Circulados em vermelho os ataques que coincidem com a clave 223222 3; em laranja os ataques um pouco menos acentuados (pulsos 6 e 15), que sugerem variantes dos tempos de 3 pulsações. Diferentemente de TOUSSAINT, que ordena a numeração de pulsos de 0 a 15, optamos por numerar de 1 a 16, pois assim se torna mais direta a comparação com as 16 "semicolcheias" que a escrita musical tradicional utiliza. Outra diferença é que TOUSSAINT interliga os pulsos atacados inserindo um polígono no círculo e, a partir daí, estuda propriedades geométricas que tal figura pode sugerir. 
ERNICA, Mauricio; MOLINA, Sergio (2016). A sagração da Portela: música, letra e contexto social na produção de reações estéticas em um samba-enredo. Per Musi. Ed. por Fausto Borém, Eduardo Rosse e Débora Borburema. Belo Horizonte: UFMG, n.34, p.177-205.

simétricos, com acentos e subdivisões regulares, e propicia que a narrativa melódica e o processo harmônico se desenvolvam.

Analisemos um pouco mais o ritmo do cavaquinho em Portela na avenida. A clave que compreende o ritmo do terceiro e do quarto compasso da introdução será repetida (como modelo para variações) a partir do compasso cinco. Na figura abaixo apresentamos as figuras rítmicas do cavaquinho nos primeiros quatro compassos:

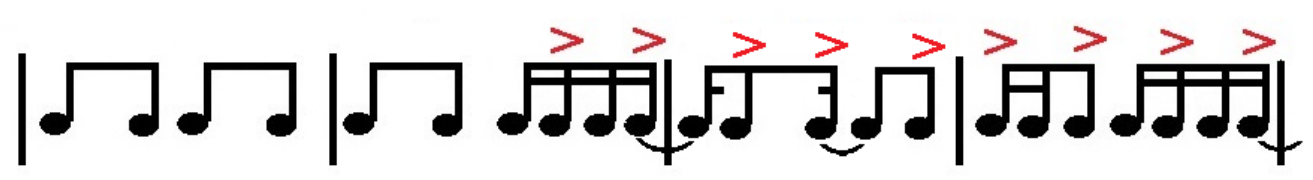

Figura 5: Cavaquinho em Portela na avenida - c.1-4

Na Figura 6, abaixo, selecionamos apenas o trecho que se repetirá como clave, os compassos 4 e 5:

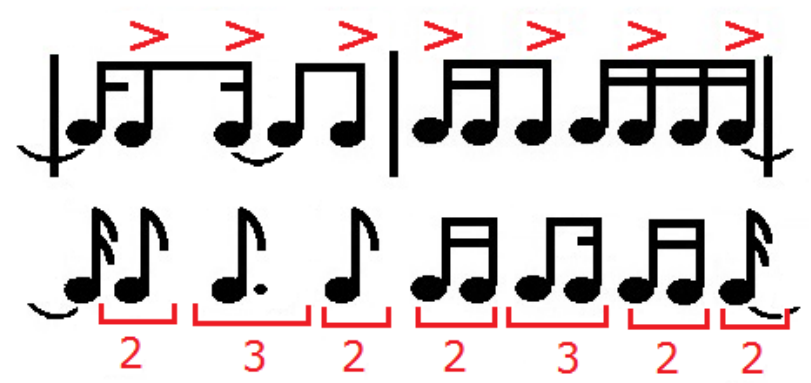

Figura 6: Clave do cavaquinho - c.4 e 5 - Portela na avenida

Levando-se em consideração os ataques e os acentos, observa-se na segunda disposição que os 16 pulsos (semicolcheias) são atacados, a partir do segundo pulso, da seguinte forma $2+3+2$ $+2+3+2+2$. Essa disposição pode ser entendida como uma rotação do paradigma do Estácio, como se a clave original (a do Estácio), estivesse se iniciando agora a partir da última colcheia do compasso 4 (o primeiro compasso da figura acima). Na figura abaixo temos a comparação da clave do Estácio e da clave do cavaquinho de Portela na avenida, levando-se em conta apenas os ataques principais: 

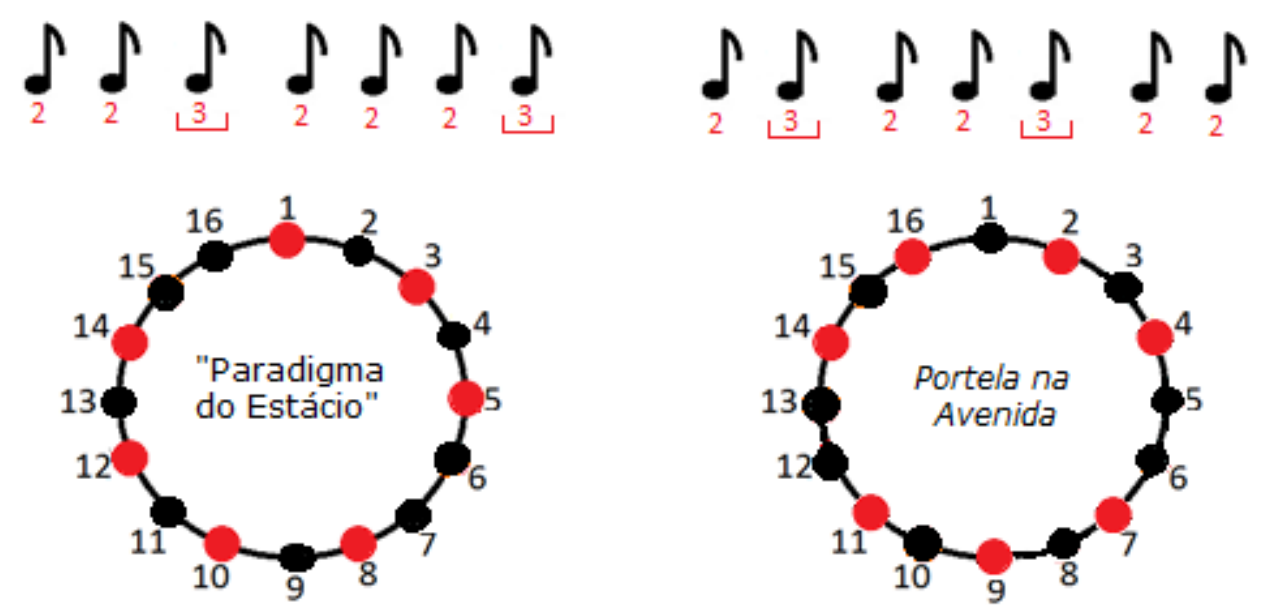

Figura 7: Rotação da clave

Pode-se notar que o modelo do Estácio $(2+2+3+2+2+2+3)$ acontece a partir do sétimo pulso do ciclo de Portela na avenida. No caso de Portela na avenida, a clave segue o padrão $2+$ $3+2+2+3+2+2$ (uma rotação do modelo do Estácio).

Chama a atenção o fato de que a clave do cavaquinho em Portela na avenida, além de estabelecer a rotação que apontamos acima, não ataca o primeiro pulso, fazendo com que a própria relação rítmica que se dá entre o cavaquinho e os outros instrumentos de percussão da base seja ainda mais sutil e complexa. No fonograma é possível ouvir outros instrumentos afirmando claramente os tempos 1 e 2 do compasso regular simétrico ${ }^{22}$.

Aprofundando um pouco a análise da base de Portela na avenida, notamos, assim, várias camadas superpostas de diferentes células rítmicas que podem obedecer a diferentes princípios de organização dos ataques, estabelecendo ciclos de diferentes durações, defasando e rotacionando claves comuns ao gênero matriz (samba). Isso tudo que acontece no âmbito do que poderíamos chamar de uma "polirritmia de estado" (a da base de dois compassos) também estabelece inúmeras possibilidades de enfrentamento com o contexto mais horizontal e narrativo dos períodos criados pelo desenrolar da melodia e da harmonia, impactando o ouvinte com um universo de nuanças e de tensionamentos de diferentes ordens, particularizando, consequentemente, a reação estética à obra.

22 A frase rítmica do surdo, por exemplo, que afirma o tempo 1 e acentua o tempo 2. 


\title{
6 - Portela na avenida - A produção da reação estética
}

\author{
Portela na avenida (Mauro Duarte e Paulo César Pinheiro)
}

1. Portela

2. Eu nunca vi coisa mais bela

3. Quando ela pisa a passarela

4. E vai entrando na avenida

5. Parece

6. A maravilha de aquarela que surgiu

7. O manto azul da padroeira do Brasil

8. Nossa Senhora Aparecida

9. Que vai se arrastando

10. E o povo na rua cantando

11. É feito uma reza, um ritual

12. É a procissão do samba abençoando

13. A festa do divino carnaval

14. Portela

15. É a deusa do samba, o passado revela

16. E tem a velha guarda como sentinela

17. E é por isso que eu ouço essa voz que me chama

18. Portela

19. Sobre a tua bandeira, esse divino manto

20. Tua águia altaneira é o Espírito Santo

21. No templo do samba

22. As pastoras e os pastores

23. Vêm chegando da cidade, da favela

24. Para defender as tuas cores

25. Como fiéis na santa missa da capela

26. Salve o samba, salve a santa, salve ela

27. Salve o manto azul e branco da Portela

28. Desfilando triunfal sobre o altar do carnaval

A letra de Portela na avenida é construída em primeira pessoa de modo declarativo, sem se dirigir a um interlocutor específico. 0 segmento que vai do verso 1 ao 21, correspondendo a toda a Seção A da canção (Figura 2), pode ser lido como um único mundo discursivo ${ }^{23}$ no qual os atributos da escola são apresentados, definindo o que a Portela é. Nesse segmento, o enunciador está implicado no discurso, sendo o fiador de sua veracidade, mas o conteúdo temático está disjunto da situação de produção encenada pela letra, estando situado fora do aqui e agora da enunciação, em uma espécie de estado atemporal; nos termos de BRONCKART

23 BRONCKART (1999) define mundos discursivos como realidades psicossociais que possibilitam o engajamento de agentes em uma interação de linguagem por meio da instauração de uma zona de interface entre representações individuais e representações coletivas mobilizadas nessa interação. Uma vez que esses mundos são, necessariamente, realizados por unidades das línguas naturais e que podem ser identificados nos textos, eles formam os tipos discursivos. 
ERNICA, Mauricio; MOLINA, Sergio (2016). A sagração da Portela: música, letra e contexto social na produção de reações estéticas em um samba-enredo. Per Musi. Ed. por Fausto Borém, Eduardo Rosse e Débora Borburema. Belo Horizonte: UFMG, n.34, p.177-205.

(1999), esse mundo corresponde ao tipo discursivo relato interativo. Vimos anteriormente que a circularidade da base rítmica também compartilha dessa experiência de presentificação do tempo.

Nesse primeiro segmento, a beleza jamais vista pelo enunciador é a Portela, cujo desfile, quando se inicia, é associado a uma procissão religiosa em devoção à padroeira do Brasil, Nossa Senhora Aparecida. A Portela, desse modo, é apresentada como símbolo e manifestação de duas instâncias supraindividuais: o Brasil e o sagrado.

0 verso 17 [e é por isso que eu ouço uma voz que me chama] pode ser lido como uma interrupção momentânea desse primeiro mundo discursivo e breve instauração de um outro mundo discursivo, no qual o conteúdo temático e o contexto de realização do texto estão em conjunção: o que é narrado está presente no aqui e agora da situação de enunciação; nos termos de BRONCKART (1999) esse segundo mundo discursivo corresponderia ao tipo discursivo discurso interativo. Veremos a seguir que a voz que chama o narrador é a da materialização da beleza eterna (sagrada e nacional) da escola.

A partir do verso 21 [No templo do samba], o que havia sido afirmado anteriormente, situado em um presente atemporal, pode ser observado in loco pelo enunciador e por aqueles que o ouvem. 0 verso 21 completa a transição dos dois mundos discursivos, do relato interativo para o discurso interativo, uma vez que pode ser tanto a conclusão do verso 20 [Tua águia altaneira é o Espírito Santo / no templo do samba] como a introdução do verso 22 [No templo do samba, / as pastoras e os pastores...]. A transição entre esses dois mundos discursivos se dá também na forma musical da canção, na passagem da Seção A para a Seção B (Figura 2).

Assim, o segmento do verso 21 ao 25 apresenta, em processo, a chegada dos membros da escola na passarela, como se estivessem atualizando e concretizando a verdade eterna (sagrada e nacional) declarada anteriormente. Musicalmente, o centro original da Seção A, Ré menor, se desloca para o terceiro grau da escala, a relativa Fá maior. À movimentação das pastoras e dos pastores (verso 22) se dá paralelamente a alternância pendular da dominante de Fá maior (Do maior com sétima menor) e o próprio Fá. 0 novo mundo discursivo é também um novo centro 
ERNICA, Mauricio; MOLINA, Sergio (2016). A sagração da Portela: música, letra e contexto social na produção de reações estéticas em um samba-enredo. Per Musi. Ed. por Fausto Borém, Eduardo Rosse e Débora Borburema. Belo Horizonte: UFMG, n.34, p.177-205.

gravitacional na harmonia.

No novo mundo discursivo, a informação que se acrescenta é que aqueles que fazem a Portela existir - e realizam sua natureza eterna, sagrada e nacional - são pessoas que chegam "da cidade, da favela" (verso 23), termos que marcam a cisão de classes sociais da cidade do Rio de Janeiro. Assim, a Portela opera também uma síntese social, outra evidência de sua natureza geral. Situada acima das classes sociais (como Nossa Senhora Aparecida), a Portela é popular.

Até aqui, a tensão no interior da letra se dá entre esses dois mundos discursivos, um declarando propriedades gerais definidoras do que é a Portela em um estado atemporal, outro testemunhando sua chegada no aqui e agora da enunciação. Nesses dois mundos, a articulação dos fenômenos feita pelos mecanismos de coesão verbal indica algo que se manifesta em um processo: o momento desde que a Portela pisa a passarela, vai entrando nela e desfila. Musicalmente, podemos observar um paralelismo entre a entrada da Portela na passarela e o movimento gerado pela melodia, que insiste em invadir a todo tempo, em processo, o universo circular da base rítmica da percussão, desencadeando e se apoiando na movimentação harmônica da canção.

Entre os dois mundos discursivos, porém, não há propriamente oposição, mas, antes, homologia e complementariedade. 0 desfile que vai se realizando no exato momento da enunciação permite a verificação e a experimentação do que havia sido enunciado como verdade geral.

A síntese será operada nos versos finais, 26, 27 e 28. Nesse momento, a escola já chegou, já está presente inteira, em pleno desfile. Esses versos de saudação à Portela, ao que ela simboliza e ao seu desfile, além da exaltarem seu caráter eterno, sagrado, nacional e popular, representam a confirmação, pela experiência, das propriedades enunciadas. 0 desfecho da canção é, por assim dizer, uma verdade que se manifesta e se impõe aos sujeitos, no exato momento da enunciação. Musicalmente, é justamente quando a letra diz salve ela e Portela que o acorde de Ré menor, centro inicial da canção, é retomado, mas agora como sexto grau do contexto harmônico gravitacional de Fá maior. 
ERNICA, Mauricio; MOLINA, Sergio (2016). A sagração da Portela: música, letra e contexto social na produção de reações estéticas em um samba-enredo. Per Musi. Ed. por Fausto Borém, Eduardo Rosse e Débora Borburema. Belo Horizonte: UFMG, n.34, p.177-205.

No fonograma analisado, a forma musical completa [A (a1 - a2 - b - a1' - a2') - B] (Figura 2) é executada duas vezes. Na primeira, a voz de Clara Nunes está em primeiro plano, sobre a base rítmica constituída pela percussão e pelo cavaquinho, e é ladeada pelo contraponto das linhas de baixo de um violão. A melodia, protagonista na sonoridade geral da canção, é interpretada pela cantora que encena o enunciador da letra, apresentando, pelo discurso, o que é a Portela.

Na segunda vez em que a letra é cantada, o arranjo reorganiza os planos e as tensões entre melodia/harmonia/letra e ritmo. A estrutura formada por letra, melodia e harmonia, por sua natureza processual, segue o curso da canção, ao mesmo tempo em que regula a presença da base rítmica formada pela percussão, produtora de estados que vão se intensificando em sua circularidade. 0 movimento da forma, portanto, vai intensificando as emoções geradas, seja pelos ciclos rítmicos, seja pela letra.

A solução formal para as tensões acumuladas é oferecida por modificações no arranjo, que reorganiza os planos. A percussão ganha em relevo, os tamborins se destacam na Seção A e os agogôs são agregados à Seção B; o coro ocupa o lugar da voz solo, que, esmaecida, deixa-se envolver pela multidão. Agora, quem protagoniza não é mais o indivíduo, mas sim o conjunto, como a encenar a presença da escola, tal qual um samba-enredo.

A introdução do coro traz à cena o coletivo, a Portela, acrescentando, pela repetição replanificada da base rítmica, uma energia emocional que será retida até o momento final, o da repetição dos três últimos versos. A convenção rítmica, os dois ataques no prato²4, e a própria ideia de retorno que também estanca o discurso melódico-harmônico intensificam e adensam o universo sonoro que envolve a reiteração da letra, como se figura e fundo finalmente explodissem juntos em uma solução que apenas poderia se dar num impensável terceiro plano, que sustenta, derradeiramente, o clímax da situação de "estado" com um congelamento do "processo".

Os três versos finais que saúdam a escola [salve o samba, salve a santa, salve ela / salve o manto

24 A partir de 3'30". 
ERNICA, Mauricio; MOLINA, Sergio (2016). A sagração da Portela: música, letra e contexto social na produção de reações estéticas em um samba-enredo. Per Musi. Ed. por Fausto Borém, Eduardo Rosse e Débora Borburema. Belo Horizonte: UFMG, n.34, p.177-205.

azul e branco da Portela / desfilando triunfal sobre o altar do carnaval] e seus significados, cantados duas vezes efusivamente, impõem-se como se ali a escola estivesse de fato presente, manifestando suas propriedades apontadas. Essa repetição se coloca como uma solução catártica da canção, fazendo com que, pelo contorno da melodia, a energia produzida pelos estados da base rítmica ecloda, rompendo seus limites e se impondo para além de si mesma, sobre o corpo do ouvinte. Materializada em letra e música, a presença da escola se impõe integralmente, operando uma verdadeira sagração da Portela.

\section{Considerações finais}

Este artigo apresenta uma proposta de análise da canção popular que busca superar dicotomias. Antes de tudo, seguindo CANDIDO (1976; 1993; 1995; 2003), analisa, relacionando-as, tanto elementos de sua estrutura interna, quanto elementos do contexto sócio-histórico do qual é produzida e apropriada por um público. No que diz respeito à abordagem da estrutura interna da canção, o artigo tem em mente a superação de duas dicotomias: primeiro, procura analisar tanto elementos textuais, da letra, como elementos estritamente musicais, para o quê mobiliza recursos de teorias interacionistas da linguagem, como BRONCKART (1999), e de recursos teóricos de musicólogos, como AROM (1991), SANDRONI (2001) e TOUSSAINT (2013); segundo, a partir da obra de VIGOTSKI (1917; 1925a; 1925b; 1934), procura analisar as relações entre forma e conteúdo, entendendo que a relação entre elas é produtora da reação estética.

Sendo assim, a interpretação de Portela na Avenida é um estudo de caso pelo qual se pretende explorar e exemplificar possibilidades dessa abordagem, que é apresentada inicialmente em seus fundamentos teóricos. Em resumo, no que diz respeito ao contexto sócio-histórico desta canção, analisamos suas vinculações com o gênero samba-enredo, de formação mais recente, e com outra tradição, mais antiga, de sambas que exaltam uma região e/ou um grupo. A canção foi gravada e fez sucesso em um momento no qual o samba e o carnaval já eram fortemente associados à identidade nacional mas que, contraditoriamente, outros gêneros musicais disputavam o espaço no campo da música popular. Portela na Avenida pode ser lido, então, como 
ERNICA, Mauricio; MOLINA, Sergio (2016). A sagração da Portela: música, letra e contexto social na produção de reações estéticas em um samba-enredo. Per Musi. Ed. por Fausto Borém, Eduardo Rosse e Débora Borburema. Belo Horizonte: UFMG, n.34, p.177-205.

um dos sambas desta época que buscam atualizar no presente a tradição.

Ao analisarmos as estruturas propriamente musicais, identificamos atritos específicos a essa linguagem, como os enfrentamentos entre os estados cíclicos (simétricos e assimétricos) das interações rítmicas de base e os processos narrativos da harmonia e da melodia. Ainda na abordagem interna, observamos como tais relações ganham em complexidade e se potencializam na medida em que as soluções composicionais são observadas na perspectiva do discurso poético verbal enunciado pela letra da canção.

Quando abordamos a letra de Paulo César Pinheiro, verificamos que havia uma tensão em seu interior entre um mundo discursivo no qual declara, atemporalmente, propriedades gerais definidoras do que é a Portela e outro no qual se testemunha, aqui e agora da enunciação, sua presença. Ao passo que a escola pisa a passarela, um processo se anuncia, a sua presentificação. Musicalmente, observamos que a melodia insiste em invadir a todo tempo, em processo, o universo circular da base rítmica da percussão, desencadeando e se apoiando na movimentação harmônica da canção.

Ao final, observando a canção como um todo, apontamos como o arranjo pôde, passo a passo, intensificar movimentos e tipologias emocionais contrastantes e propusemos a identificação de momentos específicos do fonograma nos quais suas tensões internas se resolveriam na produção de uma realidade nova e inesperada em que o processo de presentificação da escola de samba parece se congelar e se reproduzir ciclicamente, como a remeter a escola e aqueles que a assistem, no aqui e agora da enunciação, à experimentação de suas características atemporais.

\section{Referências}

1. AROM, S. (1991). African Polyphony and Polyrhythm. Cambridge: Cambridge University Press.

2. BOURDIEU, P. (2011). "A gênese dos conceitos de habitus e campo". In: 0 poder simbólico. Rio de Janeiro: Bertrand Brasil.

3.__ (2007). "Campo do poder, campo do poder, habitus de classe". In: A economia das trocas simbólicas. São Paulo: Perspectiva. 
ERNICA, Mauricio; MOLINA, Sergio (2016). A sagração da Portela: música, letra e contexto social na produção de reações estéticas em um samba-enredo. Per Musi. Ed. por Fausto Borém, Eduardo Rosse e Débora Borburema. Belo Horizonte: UFMG, n.34, p.177-205.

4. BRONCKART, J.-P. (1999). Atividades de linguagem, textos e discursos: por um interacionismo sócio-discursivo. São Paulo: Educ.

5. CANDIDO, A. (2003). "A literatura e a formação do homem". In: Textos de intervenção. São Paulo: Cia. das Letras.

6. (1993). Formação da literatura brasileira (introdução). 6a ed. Belo Horizonte:

Itatiaia.

7. (1976). Literatura e sociedade. 5a ed. São Paulo: Cia. Editora Nacional.

8. (1995). “O direito à literatura”. In: Vários escritos. São Paulo: Duas Cidades.

9. CHAMPAGNE, P.; CHRISTIN, O (2012). Pierre Bourdieu: une initiation. Lyon: PUL.

10. CLOT, Y. (2002). La fonction psychologique du travail. 3ème édition augmentée. Paris: PUF.

11. CLOT, Y. (2003). "Vygotski, la conscience comme liaison". In: Lev S.Vygotski: Conscience, inconscient, émotions. Paris: La Dispute.

12. ERNICA, M. (2008). "Le développement humain chez Vygotski: Pensée et Langage réexanimé sur le base des écrits de 1925". Cahiers de l'ILSL. Lausanne, v.24, p.43-57.

13. ERNICA, M. (2006). 0 vivido, o possível e o cartártico: para uma abordagem vigotskiana do estudo de representações sociais em textos artísticos. Tese de doutorado. LAEL - PUC/SP.

14. MARTINS, J.S. (1975). “Música sertaneja, a dissimulação na linguagem dos humilhados”. In: Capitalismo e tradicionalismo. São Paulo, Livraria Pioneira Editora.

15. MOURA, R. (1983). Tia Ciata e a pequena África no Rio Janeiro. Rio de Janeiro, Funarte.

16. SANDRONI, C. (2001). Feitiço decente: transformações do samba no Rio de Janeiro, 1917-1933. Rio de Janeiro: Jorge Zahar e Ed.UFRJ.

17. SEVERIANO, J.; MELLO, Z.H. (1997). A canção no tempo: 85 anos de músicas brasileiras - v.1: 1901-1957. São Paulo: Ed. 34.

18. (1999). A canção no tempo: 85 anos de músicas brasileiras - v.2: 1958-1985.

São Paulo: Ed. 34.

19. TINHORÃO, J.R. (1998). História social da música popular brasileira. São Paulo: Ed. 34.

20. TOUSSAINT, G.T. (2013). The geometry of musical rhythm. Boca Raton: CRC Press.

21. VIANNA, H. (1999). 0 mistério do samba. Rio de Janeiro: J.Zahar e Ed.UFRJ.

22. VIGOTSKI, L.S. (1917). A tragédia de Hamlet, príncipe da Dinamarca. São Paulo: Martins Fontes, 1999. 
ERNICA, Mauricio; MOLINA, Sergio (2016). A sagração da Portela: música, letra e contexto social na produção de reações estéticas em um samba-enredo. Per Musi. Ed. por Fausto Borém, Eduardo Rosse e Débora Borburema. Belo Horizonte: UFMG, n.34, p.177-205.

23. VIGOTSKI, L.S. (1925a). "La conscience comme problème de la psychologie du comportement”. In: Conscience, inconscient, émotions. Paris: La Dispute, 2003.

24. VIGOTSKI, L.S. (1934). Pensée et langage. 3ème éd. revue. Paris: La dispute, 1997.

25. VIGOTSKI, L.S. (1925b). Psicologia da arte. São Paulo: Editora Martins Fontes, 1999.

26. VOLOCHINOV, V.N. (1926). "Discours dans la vie et discours dans la poésie". In: Todorov, T. Mikhaïl Bakhtine et le principe dialogique - suivi d'Écrits du Cercle de Bakhtine. Paris:

Editions du seuil, 1981.

27. WISNIK, J.M. (1989). 0 som e o sentido. São Paulo: Companhia das Letras, Círculo do Livro.

\section{Referências de vídeos}

1. SOLBERG, H. (2008). A palavra en-cantada. Brasil (Documentário).

Nota sobre os autores

Mauricio Ernica é docente do Departamento de Educação, Conhecimento, Linguagem e Arte da Faculdade de Educação da Unicamp. É cientista social (USP, 1995), mestre em Antropologia Social (Unicamp, 1999) e doutor em Linguística Aplicada e Estudos da Linguagem (PUC-SP, 2006). Seus temas de investigação são: representações sociais em letras de música, linguagem e desenvolvimento, e desigualdades educacionais.

Sergio Molina é docente da Faculdade Santa Marcelina (SP), onde coordena a Pós-Graduação Canção Popular: criação, produção musical e performance, e é professor de composição no Instituto Carlos Gomes em Belém (PA). É graduado em Composição pela Escola de Comunicação e Artes da USP (1991), mestre em Musicologia pela mesma instituição (2004) e doutor em Processos Criativos também na ECA-USP (2014). Como compositor e pesquisador, Sergio Molina investiga as interações entre os universos da música clássica e da popular. 